\title{
La Organización de Ciudades del Patrimonio Mundial, Foro de Encuentro y Solidaridad
}

José Manuel Molina García

Presidente de la OCPM y Alcalde de Toledo

\section{Resumen}

En el texto se realiza una presentación de la Organización de las Ciudades del Patrimonio Mundial, entidad que, desde octubre de 200I, está presidida por la ciudad española de Toledo. Fundada en 1993, la OCPM reúne a más de 180 ciudades que tienen en su territorio algún sitio inscrito por la UNESCO en la Lista del Patrimonio Mundial. Se explican asimismo los fines y proyectos de interés de esta organización que fomenta, entre sus objetivos principales, la cooperación y el intercambio de información y de conocimientos entre todas las ciudades históricas del mundo.

\section{Palabras clave}

Ciudades del Patrimonio Mundial / UNESCO / Turismo / Conservación / OCPM

Ya se han cumplido cuarenta años desde que la UNESCO lanzase un llamamiento a todo el mundo a favor de los monumentos egipcios de Nubia, amenazados por la construcción de la presa de Asuán. Aquel llamamiento internacional contribuyó a incentivar la adopción de políticas a favor de la conservación y rehabilitación del patrimonio. Tras la aprobación en 1972 de la Convención para la Protección del Patrimonio Mundial Cultural y Natural, en las últimas décadas las acciones conservacionistas han sido una dinámica esencial en todo el mundo. Afortunadamente hoy nos encontramos en una etapa apasionante en la que se ha avanzado considerablemente en la conservación de nuestra riqueza monumental. La publicación de este informe especial en el PH Boletín del Instituto Andaluz del Patrimonio Histórico es otro exponente más de ese interés.
La conservación del patrimonio histórico-artístico constituye un reto común para todas las ciudades que gozamos de tal consideración y estamos inscritas en la Lista de Patrimonio Mundial de la UNESCO. En líneas generales podemos decir que la dinámica social de los tiempos actuales ejerce una importante presión sobre los centros urbanos antiguos. Así, nos encontramos con problemas de población por demasía o exceso, deterioro de las infraestructuras por la gran presión del turismo, dificultades con el tráfico rodado y los transportes, o especulaciones de bienes mobiliarios o inmobiliarios. Estos son algunos de los obstáculos con que se tropiezan en todos los continentes para elaborar políticas eficaces de conservación de los barrios históricos.

Para dar respuesta a todo ello, así como favorecer la cooperación y el intercambio de información y de conocimiento entre todas las ciudades históricas del mundo, nació la Organización de las Ciudades del Patrimonio Mundial, entidad que desde octubre de 200 I está presidida por la ciudad española de Toledo, de la cual tengo la enorme satisfacción de ostentar su Alcaldía. Quiero, por tanto, centrar este artículo en una presentación de nuestra Organización, así como de sus fines, objetivos y proyectos.

La OCPM tiene como fin fundamental favorecer la cooperación y el intercambio de información y de conocimientos entre todas las ciudades históricas del mundo, en estrecha colaboración con los organismos internacionales que persiguen objetivos análogos. En la misma está excluida la búsqueda de objetivos de tipo ideológico, político, religioso, étnico y racial. La Secretaría General de la entidad está ubicada en la ciudad de Quebec. Hasta ahora la entidad ha sido presidida por las ciudades canadiense de Quebec y noruega de Bergen, siendo Toledo la primera ciudad de habla hispana que ostenta su representación presidencial. En apoyo a su Secretaría General se disponen de cinco Secretarías Regionales: Bergen (Noruega) para Europa del Norte-Oeste; Budapest (Hungría) para Europa Central y Oriental; 


\section{A partir de ahora trabajaremos conjuntamente en potenciar la comunicación e intercambio de informaciones y experiencias entre las ciudades del Patrimonio Mundial; en el desarrollo turístico de las ciudades históricas, procurando que este fenómeno masivo sea respetuoso con la conservación de la vitalidad y carácter pro- pio de cada urbe}

Guanajuato (México) para América Latina; Túnez para África del Norte y Córdoba (España) para el Sur del Mediterráneo. El actual Consejo de Administración de la Organización de las Ciudades del Patrimonio Mundial está conformado por Santiago de Compostela, Kandy (Sri Lanka), Luxemburgo, Puebla de los Ángeles, Cuenca (Ecuador), Évora (Portugal), Vilnius (Lituania) y Toledo.

\section{Un patrimonio de 120 millones de habitantes}

El 8 de septiembre de 1993 se fundaba en la localidad marroquí de Fez, la Organización de las Ciudades del Patrimonio Mundial, que reúne a más de 180 ciudades que tienen en su territorio algún sitio inscrito por la UNESCO en la Lista del Patrimonio Mundial. En su conjunto, estas ciudades tienen una población que supera los 120 millones de habitantes. La creación de esta organización es consecuencia directa de las conclusiones adoptadas en el año 199| en el Primer Coloquio Internacional de las Ciudades del Patrimonio Mundial, convocado por los gobiernos de Québec y de Canadá, bajo los auspicios de la UNESCO, a cuyo término se expresó el deseo de constituir una red de ciudades del Patrimonio Mundial

Entre los objetivos y funciones de la Organización de las Ciudades del Patrimonio Mundial figuran los siguientes:

- Contribuir a la aplicación de la Convención sobre la Protección del Patrimonio Mundial Cultural y Natural y de la Carta Internacional para la Salvaguarda de las Ciudades Históricas.

- Fomentar la cooperación y el intercambio de información sobre las Ciudades del Patrimonio Mundial y establecer una estrecha colaboración con las demás instituciones y organizaciones internacionales y regionales que posean objetivos análogos.

- Fomentar y contribuir al establecimiento de una red de relaciones entre las poblaciones de las ciudades miembros por medio de la organización de pro- gramas de -intercambios que puedan apoyar los esfuerzos de las ciudades situadas en los países en desarrollo.

- Permitir que cada una de las ciudades miembros de la Organización saque provecho de la pericia de todas las demás y de las soluciones que éstas hayan encontrado para resolver sus problemas

- En colaboración de organismos especializados tales como "International Council on Monuments and Sites" (ICOMOS), "Union Internationale pou la Conservation de la Nature et de ses Ressources" (UICN), "International Council of Museums" (ICOM) e "International Centre for the Study of Preservation and Restoration of Cultural Property" (ICROM), centrar mejor los estudios e investigaciones de los especialistas y expertos en las necesidades de los responsables de la administración municipal.

- Tomar todos los medios necesarios para que a las Ciudades del Patrimonio Mundial no se las considere más como objetivos militares en ningún acto de beligerancia y velar por el respeto de ese reconocimiento.

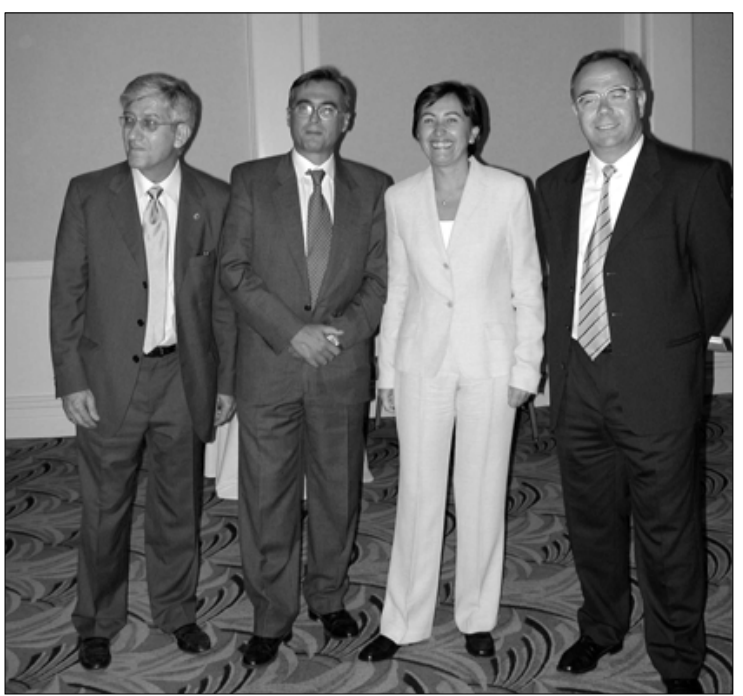

Alcaldes de Segovia, Toledo, Córdoba y Santiago de Compostela durante la Asamblea de Puebla 


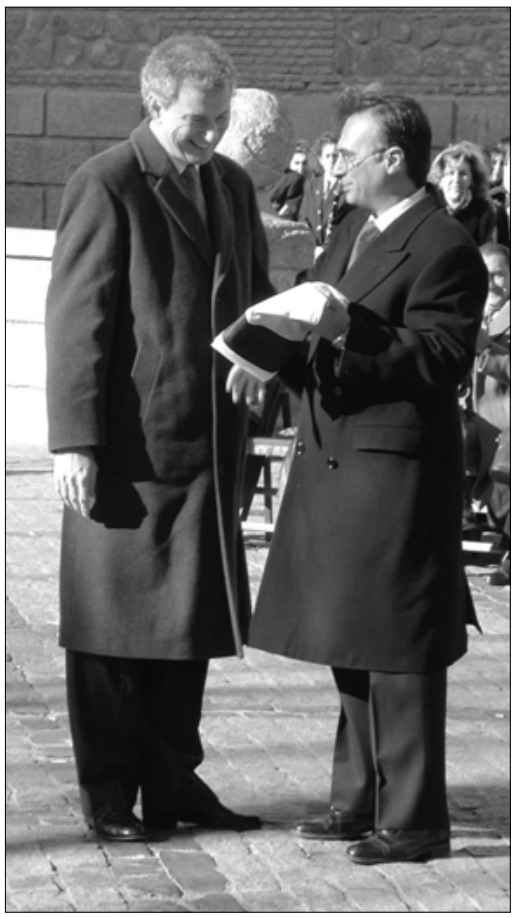

e la Ricard, secretario general de Toledo la bandera de la organización como símbolo de la actual Presidencia
Banco de datos sobre las ciudades del Patrimonio Mundial

Su finalidad es mantener un sitio web, trilingüe, destinado a proporcionar información sobre la OCPM, asegurando la visibilidad de las ciudades del Patrimonio Mundial y favorecer el intercambio de los conocimientos técnicos entre los gestores de las ciudades históricas. Asimismo se ha desarrollado un sistema informático de gestión de los bancos de datos textuales y gráficos sobre las Ciudades del Patrimonio Mundial y de una manera más amplia sobre las ciudades históricas.

\section{Formación de gestores municipales}

Todos los años impares la OCPM organiza un coloquio internacional sobre algún aspecto destacado en el ámbito de los desafíos de gestión con que se enfrentan las Ciudades del Patrimonio Mundial. El próximo tendrá lugar en Rodas. Asimismo, coincidiendo con las reuniones del Consejo de Administración de la Organización se suelen convocar seminarios dirigidos a profundizar sobre una problemática dada entre los gestores municipales y los expertos en patrimonio. Otros ámbitos de actuación en este apartado son la elaboración de programas de formación, el apoyo a las convocatorias regionales que traten sobre estrategias para la revalorización y conservación de los conjuntos urbanos históricos, y la difusión de la información de las diferentes sesiones de formación gestión, así como sobre las estrategias de valoración y de conservación de los conjuntos históricos. En el último de los coloquios, el celebrado en la ciudad mexicana de Puebla en el pasado año, se debatió sobre las medidas de prevención y de prevención para las ciudades del Patrimonio Mundial en caso de desastre.

Junto a las conclusiones de este Coloquio, a lo largo de su historia la OCPM ha ido generando una importante serie de documentos que muestran el punto de vista de sus miembros sobre algunos de los principales problemas que afectan a las ciudades patrimoniales. Así, por ejemplo, el "Llamamiento de Évora" (1997) se decanta a favor de un desarrollo turístico preocupado de salvaguardar la vitalidad y el carácter de las ciudades históricas; en el "Manifiesto de Santiago de Compostela" (1999) se muestra a favor de la cooperación en la conservación activa y gestión sostenible de las ciudades Patrimonio de la Humanidad; y el "Protocolo de Bergen" (1995) aboga sobre comunicación y el intercambio de experiencias entre las ciudades patrimoniales.

\section{Los grandes proyectos de la OCPM}

Dentro de sus actividades ordinarias, la OCPM mantiene una serie de grandes proyectos, entre los que destacan los siguientes:

\section{La Guía de Gestión}

Con el propósito de estimular el intercambio continuo entre las personas encargadas de la gerencia diaria en las Ciudades Históricas, en nuestra página web pueden consultarse los pormenores de una denominada Guía de Gestión, que está concebida como un práctico manual con ejemplos prácticos y estudios concretos. La intención del material presentado en esta Guía no es proporcionar fórmulas que resuelvan los problemas de conservación, sino fomentar la comprensión de la relación existente entre la elección de un método apropiado y las características aplicables de su contexto.

\section{Representación}

No podríamos cerrar esta capítulo sobre los grandes proyectos de la OCPM sin hacer mención a sus funciones de representación de los intereses de las ciudades del Patrimonio Mundial frente a organizaciones coparticipes como son Naciones Unidas, la UNESCO, la Organización Mundial del Trabajo, el Banco Mundial y el Consejo de Europa. Asimismo asiste a las ciudades candidatas a su inscripción en la Lista del Patrimonio Mundial de la UNESCO. 


\section{El coloquio internacional de Rodas}

Inculcar en las nuevas generaciones los principios e ideales de la conservación patrimonial debe ser uno de los objetivos prioritarios de los gestores públicos de las ciudades miembros de la OCPM. Con la vista puesta en ese objetivo, nuestra organización ha aprobado el desarrollo del proyecto "EDUCACIÓN, PATRIMONIO Y JUVENTUD", que vamos a materializar en colaboración con el Centro del Patrimonio Mundial de la UNESCO. Pretendemos que los jóvenes estudiantes y universitarios de nuestras ciudades se impliquen en divulgar y difundir el contenido de la Convención del Patrimonio Mundial y con su trabajo actúen como embajadores de buena voluntad en la defensa y promoción de los objetivos que nos han reunido en la OCPM. Este proyecto, aprobado durante la última reunión de nuestro Consejo de Administración en Zamosc, tendrá su culminación en la celebración del Foro de Jóvenes que se celebrará en la ciudad griega de Rodas en septiembre del próximo año, coincidiendo con nuestro VII Coloquio Internacional.

Anteriormente, al hablar de los fines de la OCPM hacía referencia a la colaboración con los distintos organismos internaciones, en este sentido, mantenemos un acuerdo de cooperación con la UNESCO, para la búsqueda de objetivos comunes en la protección, conservación y valoración del patrimonio mundial, favoreciendo la cooperación internacional en nuestros respectivos ámbitos de competencias, con el fin de hacer progresar el respeto universal por el patrimonio y su inserción en las políticas de desarrollo. A partir de ahora trabajaremos conjuntamente en potenciar la comunicación e intercambio de informaciones y experiencias entre las ciudades del Patrimonio Mundial; en el desarrollo turístico de las ciudades históricas, procurando que este fenómeno masivo sea respetuoso con la conservación de la vitalidad y carácter propio de cada urbe; y en la conservación y gestión de las Ciudades del Patrimonio Mundial. Dentro de este acuerdo debemos destacar que la OCPM será invitada a participar en calidad de observador en las reuniones de la UNES$\mathrm{CO}$ en las que se aborden cuestiones patrimoniales. Naturalmente, la citada organización internacional recibirá el mismo trato en nuestros encuentros.
Permítanme que, como alcalde de la ciudad de Toledo, concluya estas líneas haciendo referencia a la próxima celebración en nuestra capital de un Consejo de Administración de la OCPM, en la primavera del año 2003. La ciudad de Toledo está desarroIlando actualmente un importante proyecto de rehabilitación y revitalización de su Casco Histórico, que ha merecido los elogios del Consejo Superior de Colegios de Arquitectos de España, cuyo presidente ha manifestado públicamente que Toledo es actualmente paradigma de las intervenciones arquitectónicas en una ciudad patrimonial. De acuerdo con los fines de la OCPM y con las propuestas con las que solicité la confianza de las ciudades miembro para alcanzar la Presidencia, quiero que todos podamos compartir la experiencia que estamos llevando a cabo. Por eso, coincidiendo con esta reunión del Consejo de Administración celebraremos un Encuentro Internacional en el que se aborden cuestiones relacionadas con la conservación y la rehabilitación patrimonial. Aquí os esperamos.

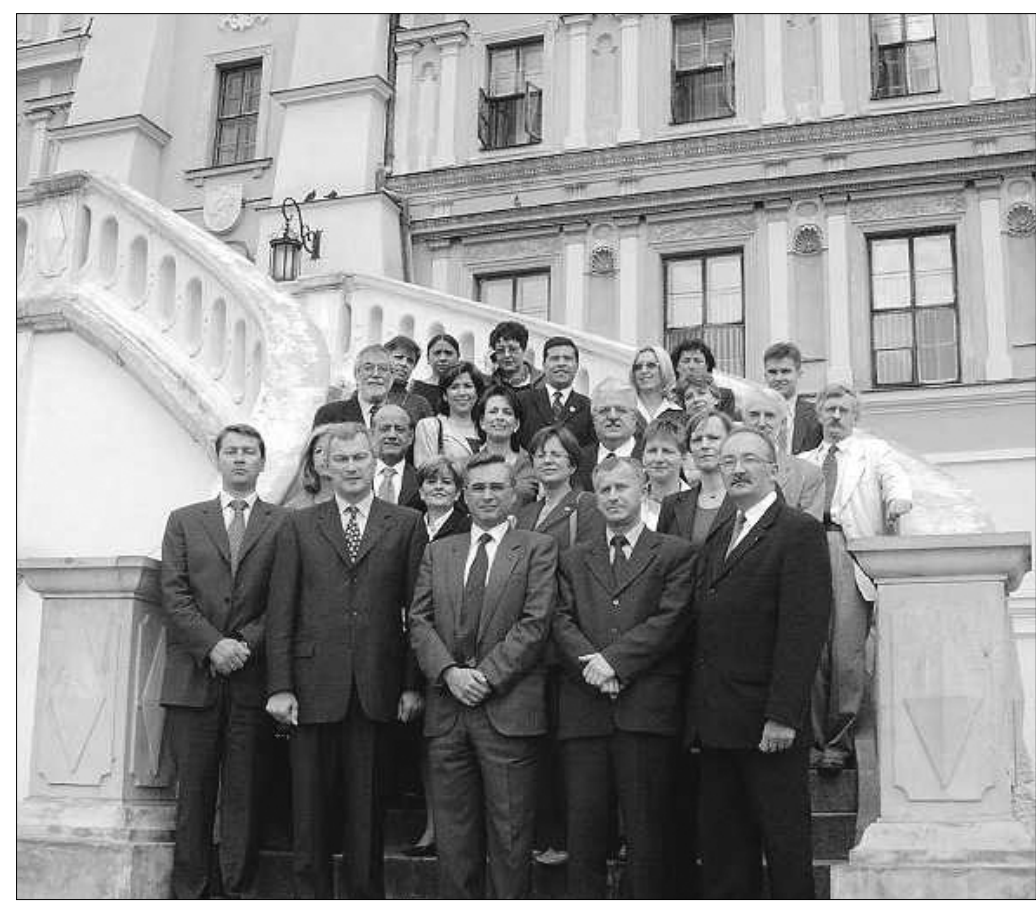

Miembros asistentes a la última reunión del Consejo de Administración de la OCPM celebrada en Zamosc (Polonia) 